\title{
Effect of the Obesity on Maternal and Fetal Outcome in Pregnant Women Presenting to Tertiary Care Hospital
}

\author{
SANA ISLAM ${ }^{1}$, SADIA ANWAR ${ }^{2}$, HUMAIRA BASHIR ${ }^{3}$, SAFIA KHAN ${ }^{4}$, AMMARA PIRZADA $^{5}$, SHERZAMAN KHAN $^{6}$ \\ ${ }^{1}$ Ex Trainee Registrar, Obs \& Gynae Federal Government Polyclinic Hospital, Islamabad \\ ${ }^{2}$ Assistant Professor, Obs \& Gynae, Mufti Mehmood Hospital, D.I.Khan \\ ${ }^{3}$ Trainee Registrar, Obs \& Gynae, Mufti Mehmood Hospital, D.I.Khan \\ ${ }^{4}$ Senior Registrar Alnafees Medical College and Hospital, Islamabad \\ ${ }^{5}$ Senior Registrar, Obs \& Gynae, Alnafees Medical College and Hospital, Islamabad \\ ${ }^{6}$ Consultant Endocrinologist BMCH, Quetta \\ Corresponding author: Sadia Anwar, Email: sasajjaddr@gmail.com, Cell: 03315894339
}

\begin{abstract}
Background: Obesity is well considered a well known risk factor for obstetric complications like pre eclampsia, gestational diabetes mellitus, intrauterine death, dysfunctional labour, meconium stained amniotic fluid, cesarean section, high birth weight and shoulder dystocia. The objective of this study was to determine the frequency of maternal and fetal outcome in obese pregnant women.

Material and Methods: This descriptive case series study was conducted in department of obstetrics and gynaecology, FGPC, Islamabad from Aug 1, 2017 to Feb 1, 2018. A total of 250 consecutive antenatal women with BMl $>30 \mathrm{Kg} / \mathrm{m}^{2}$ were included in the study. BMI was calculated according to weight and height of the patient using the formula $\mathrm{Kg} / \mathrm{m}^{2}$.

RESULTS: Out of 250 primigravidas , $84.4 \%$ had BMI of $30-35 \mathrm{Kg} / \mathrm{m}^{2}$ and $15 \% \mathrm{BMl}$ of $36-40 \mathrm{Kg} / \mathrm{m}^{2}$. Gestational diabetes was diagnosed in $51(20.4 \%)$ cases. Preeclampsia was observed in $12(4.8 \%)$ patients. Seventy pts (28\%) patients ended on cesarean section, $21(8.4 \%)$ cases had induction of labour and $9(3.6 \%)$ had pre term birth. Apgar score $(>7)$ was seen in 61 (24.4\%) cases. Macrosomia was observed in $55(22 \%)$ cases. $20(8 \%)$ patients had stillbirth.

Conclusions: Maternal obesity in pregnancy is associated with high maternal and fetal complications.

Keywords: complications. fetal, maternal; morbidity ,Obesity, overweight-; risk factors
\end{abstract}

\section{INTRODUCTION}

Obesity is an epidemic health issue globally and more than one billion adult population of the world is overweight. WHO describes obesity as "one of the most flagrantly visible and most neglected, public health problem that affects every community in the world. ${ }^{1}$ It is considered as a "killer disease" which contributes to the global burden of chronic diseases. The body mass index (BMI) is an applied tool to assess human body fat based on an individual's weight and height. It was introduced by the Belgian polymath Adolphe Quetelet in 1830. BMI of more than 30 is considered obesity. ${ }^{1}$

A local study from Karachi reported $29.1 \%$ women to be obese in ongoing pregnancy. ${ }^{2}$ Almost $33 \%$ of the American population is obese which means one in three adults in the U.S. are obese. Many young women are getting pregnant with already existing obesity leading to increased burden of high risk pregnancies and maternal mortality in developed countries. ${ }^{3}$. An Australian study reported $34 \%$ of pregnant women to be obese 4 .

Maternal obesity increases the risk of hypertension, gestational diabetes, antepartum venous thromboembolism, labour induction, caesarean delivery and wound infection. ${ }^{5}$ Perinatal complications like macrosomia, intrauterine growth restriction, still birth, preterm birth are high in obese women. ${ }^{6,7}$ which are due to fetal placental and metabolic dysfunction among obese pregnant women. ${ }^{8}$

Body mass index $(\mathrm{BMI})>30 \mathrm{Kg} / \mathrm{m}^{2}$ is a globally accepted definition for obesity. One of the most important pre disposing factor is Asian ethnicity as Asian population have high body fat percentage compared to Europeans at the same level of BMI. ${ }^{2}{ }^{9}$

The major causes of obesity are factors like inactivity, unbalanced diet and sedentary life style. It is associated with several serious and life threatening complications. In addition to physical symptoms it may also lead to mental distress, metabolic disorders, vascular diseases and osteoarthritis. ${ }^{10}$

Obesity is assessed with the help of body mass index. In pregnancy body mass index (BMI) is calculated using prepregnancy weight. If pre pregnancy weight is unknown, the first antenatal visit weight measurement is used as baseline to calculate BMI. ${ }^{11,12}$

The reported prevalence of various obstetrical complications in pregnant obese women is as follows; gestational diabetes $17 \%,{ }^{13}$ preeclampsia and pregnancy induced hypertension $14 \%,{ }^{14}$ caesarean section rate as high as $27.8 \%,{ }^{15}$ failure to progress in labor $6 \%,{ }^{16}$ vaginal birth after previous caesarean $13 \%{ }^{17}$, postpartum haemorrhage as high as $44 \%$ due to macrosomia and uterine atony. ${ }^{18}$

This study aims to assess the fetal and maternal outcome and other complications of pregnancy in obese primigravidas.

\section{MATERIAL AND METHODS}

This descriptive cases series study is conducted in the department of obstetrics and gynaecology, Federal Government Polyclinic Hospital Islamabad from Aug 1, 2017 to Feb 1, 2018.

Sample size was calculated using $\mathrm{WHO}$ sample size calculator in following statistical assumptions:

Confidence level $=95 \%$

Population proportion of IUGR in obese women $P=6 \%(1)$

Estimated Error $\quad d=3 \%$

Sample size $\quad \mathrm{n}=250$ sampling.

Sampling technique was Non probability consecutive

Booked primigravida having singleton pregnancy $>12$ weeks of gestation and $\mathrm{BMI}>30 \mathrm{~kg} / \mathrm{m} 2$ were included in study while multigravida, multiple gestation, previous $\mathrm{C}$-section and cases of chronic hypertension, diabetes, epilepsy, thyroid diseases, asthma and heart diseases were excluded from study.

After approval from ethical committee, all women presenting to the antenatal clinic were screened. Women with obesity and fulfilling study inclusion criteria were selected from the antenatal clinic at FGPC, Islamabad. The demographic characteristics (age, weight, height, parity and gestational age) of enrolled women were noted. The weight of patients was measured in KG by weighing machine while height was measured in meter with measuring tape.

The patient BMI was calculated by using formula: Weight kg / height m2. The patients were enrolled after 12 weeks of gestation and details of the study parameter of maternal outcomes (preeclampsia, GDM, preterm Labour, induction of labor and c-section) were noted. They were followed till delivery to note the fetal outcomes (Birth weight, Apgar score at $1 \mathrm{~min}$ and $5 \mathrm{~min}$ and still birth) on specifically designed proforma.

The data were entered and analyzed in SPSS programme version 20.0. The quantitative variables like age, gestational age, $\mathrm{BMI}$ and birth weight of baby were measured as mean, standard 
deviation and ranges. The qualitative variables like fetal outcome and maternal outcome were measured in terms of frequency and percentages. Effect modifiers age, gestational age and base line $\mathrm{BMI}$ were controlled by stratification. Post stratification chi-square was applied. P-Value $\leq 0.05$ was considered statistically significant. The results were described and data was presented in tables and graphs.

\section{RESULTS}

This study was performed on 250 antenatal patients with a BMI > $30 \mathrm{Kg} / \mathrm{m}^{2}$. They were followed regularly in antenatal OPD as well as during labour and post partum.

The age range of population under study was $21-30$ years in $167(66.8 \%)$ cases, $31-35$ years in $80(32 \%)$ cases and $15-20$ years in $03(1.2 \%)$ patients. Minimum age in this study was 18 years and maximum was 35 years, with a mean age of 28.87 years +3.92 SD .

The gestational age of the women ranged from 28 weeks to 42 weeks, with a mean gestational age of $37.48+2.47$ weeks. In $190(76 \%)$ patients gestational age ranged from 36-40 weeks, followed by $33(13.2 \%)$ in the gestational age range of $31-35$ weeks. Twenty-two $(8.8 \%)$ patients were in the gestational age range of $>41$ weeks. Only $05(2 \%)$ patients were in the gestational age range of $28-30$ weeks .

The weight of $194(77.6 \%)$ patients was in range of 71-80 $\mathrm{Kg}$, while in $28(11.2 \%)$ patients weight ranged from $81-90 \mathrm{Kg}$, weight range $65-70 \mathrm{Kg}$ was seen in $26(10.4 \%)$ patients. In 02 $(0.8 \%)$ patients range was from $91-100 \mathrm{Kg}$. Minimum weight of the patients was $65 \mathrm{Kg}$ and maximum was $100 \mathrm{Kg}$, with a mean weight of $77.08+4.70 \mathrm{Kg}$.

In $178(71.2 \%)$ patients, height ranged from 1.61-1.70 meters, in $57(22.8 \%)$ patients, height ranged from 1.54-1.60 meters, and in $14(05.6 \%)$ patients, height ranged from 1.71-1.80 meters. Only $01(0.4 \%)$ patient was observed in height range of $1.81-1.85$ meters. Minimum height of the patients was 1.54 meters and maximum was 1.85 meters, with a mean height of $1.64+4.38$ meters .

The range of body mass index (BMI) is as follow: 30-35 $\mathrm{Kg} / \mathrm{m}^{2}$ in $212(84.8 \%)$ patients, $36-40 \mathrm{Kg} / \mathrm{m}^{2}$ in $38(15.2 \%)$ patients. Minimum BMI of the patients was $30 \mathrm{Kg} / \mathrm{m}^{2}$, and maximum was 40 $\mathrm{Kg} / \mathrm{m}^{2}$, with a mean BMl of $33.93+1.82 \mathrm{Kg} / \mathrm{m}^{2}$.

Table no. 1 : body mass index (bmi) $(n=250)$

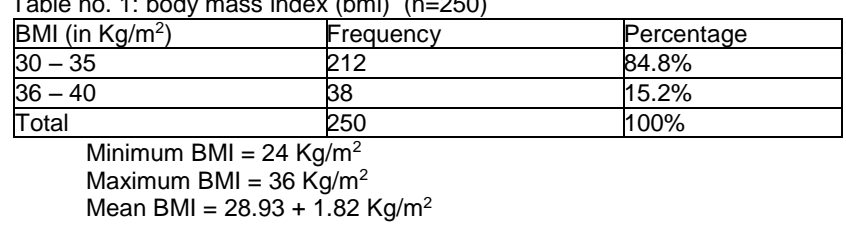

Table no. 2: frequency of various maternal and fetal complications of obesity in patients $(\mathrm{n}=250)$

\begin{tabular}{|c|c|c|}
\hline Complications & Frequency & Percentage \\
\hline $\begin{array}{l}\text { MATERNAL: } \\
\text { Medical Complications: } \\
\text { Gestational diabetes mellitus } \\
\text { Preeclampsia }\end{array}$ & $\begin{array}{l}51 \\
12\end{array}$ & $20.4 \%$ \\
\hline $\begin{array}{l}\text { Obstetrical Complications: } \\
\text { Cesarean section } \\
\text { Induction of labor } \\
\text { Pre term Birth }\end{array}$ & $\begin{array}{l}70 \\
21 \\
09\end{array}$ & $\begin{array}{l}30.4 \% \\
08.4 \% \\
03.6 \%\end{array}$ \\
\hline 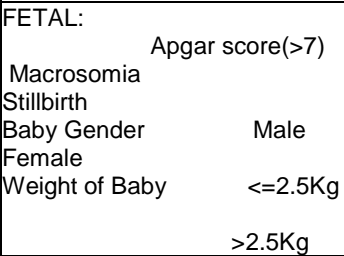 & $\begin{array}{l}61 \\
55 \\
20 \\
112 \\
138 \\
92 \\
158\end{array}$ & $\begin{array}{l}24.4 \% \\
22 \% \\
08 \% \\
44.8 \% \\
55.2 \% \\
36.8 \% \\
75.2 \%\end{array}$ \\
\hline
\end{tabular}

Out of 250 patients, 120 (48\%) had SVD, 60 (24\%) had instrumental delivery and $70(28 \%)$ were delivered through csection.

Medical disorders like hypertension and diabetes were also seen in obese antenatal patients in our study. Gestational diabetes was diagnosed in 51 (20.4\%) cases. Preeclampsia was observed in $12(4.8 \%)$ patients.

Seventy (28\%) patients delivered by cesarean section, 21 $(8.4 \%)$ cases had induction of labour and $9(3.6 \%)$ had pre term birth.

Apgar score (>7) was seen in 61 (24.4\%) cases. Macrosomia was observed in $55(22 \%)$ cases. $20(8 \%)$ patients had stillbirth, all of them were diagnosed in antenatal period by ultrasound.

Table no. 3: stratification of bmi over maternal and fetal complications of obesity in patients $(n=250)$

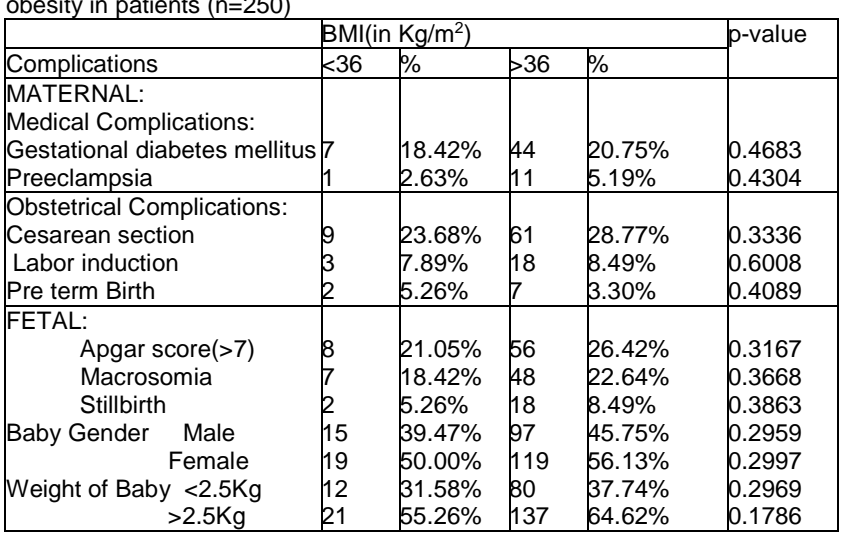

\section{DISCUSSION}

Obesity is considered the most common nutritional disorders globally. It is the result of an incorrect energy balance and eating disorders leading to excessive fat stores. It is a chronic multifactorial metabolic disorder. The high prevalence of obesity among pregnant women has various implications for antenatal care and obstetrical outcomes. In pregnancy, BMI is ideally calculated using pre-pregnant weight. ${ }^{10}$

In this study, 250 obese pregnant patients were enrolled. Their BMI on the first antenatal visit irrespective of the gestational age was calculated. In our community patients seldom report for pre-pregnancy evaluation and during pregnancy they are mostly referred when obstetrical complications like hypertension, diabetes mellitus or failure to progress of labour encounters. This makes recording of weight and BMI in early pregnancy extremely difficult or almost impossible.

The research literature demonstrates that high BMI is linked with a higher rate of perinatal and maternal complications. The results of our study are comparable with other studies.

In this study pre eclampsia was observed in $12 \%$ cases . O'Brien et $\mathrm{al}^{19}$ also demonstrated that obese pregnant women have a $14-25 \%$ incidence of $\mathrm{PIH}$. In a local study conducted by Jaleel $\mathrm{R},{ }^{9} \mathrm{PIH}$ was found in $10.1 \%$ of obese pregnant women.

Gestational diabetes mellitus (GDM) was found in $20.4 \%$ of the cases of this study. This was reported in $4 \%$ of cases $s$ by Jaleel $R,{ }^{9}$ and $17 \%$ of cases in a study by Linne $Y$ et al. ${ }^{20}$

The increased frequency of cesarean section in our study ( $28 \%$ is comparable with other studies in literature. A study by Sherrard $A^{21}$ demonstrated that pre-pregnancy BMI $>25 \mathrm{Kg} / \mathrm{m}^{2}$ increases the risk for cesarean delivery in all women irrespective of age, parity, socioeconomic status, gestational diabetes and other obstetric indications. It is well understood that slow rate of cervical dilatation and increased amount of fatty tissues in maternal pelvis may lead to labour arrest or dysfunctional labour. Jaleel $R^{2}$ observed cesarean delivery in $36 \%$ of cases and in $20 \%$ of cases by Sebrie NJ. ${ }^{23}$ 
It was observed that fetal distress is more common in obese women with increased BMI leading to failed trial of labour and nonreassuring cardiotochograpgy. Sheiner et $\mathrm{al}^{9}$ observed that women with high BMI were more likely to have induction of labour, meconium stained amniotic fluid and malpresentation.

In our study stillbirth was observed in $8 \%$ of patients. This is supported by Sebire et $\mathrm{al}^{22}$ that women with high BMI had a significantly increased risk of late fetal death. The relatively high risk of stillbirth could be due to intrauterine hyperglycemia and disturbed fetal metabolic requirements.

Our study patients demonstrated higher mean birth weight with $22 \%$ having macrosomia. These results are comparable with studies by Jaleel $\mathrm{R},{ }^{9}$ Callaway LK, ${ }^{24}$ Arendas $\mathrm{K},{ }^{25}$ Galtier $\mathrm{F},{ }^{26}$ and Abenhaim MA. ${ }^{27}$ All Asians women with high BMl are more likely to give birth to macrosomic babies independent of gestational diabetes.

Our study emphasis that obesity is an important health issue in Pakistan. Our maternity units encounter a large number of obese pregnant women with obstetrical complications. Further studies are therefore needed to highlight this public issue.

\section{CONCLUSION}

This study concludes that majority of young obese pregnant women had BMl of $>30-35 \mathrm{Kg} / \mathrm{m}^{2}$. Among the complications of obesity, gestational diabetes, macrosomia, cesarean section, stillbirth, and preeclampsia were found with varying frequencies.

\section{REFERENCES}

1. Lakhanpal S, Aggarwal A, Kaur G. To assess the effect of maternal BMI on obstetric outcome. Int J Adv Res Technol 2012; 1: 32-70

2. Ali HS, Lakhani N. Effect of obesity and its outcome among pregnant women. Pak J Med Sci 2011;27:1126-8

3. Hillemeier MM, Weisman CS, Chuang C, Downs DS, McCallHosenfeld J, Camacho F: Transition to overweight or obesity among women of reproductive age. J Womens Health (Larchmt). 2011; 20: 703-10

4. OECD, Obesity Update, June 2014. Available at: http://www.oecd.org/els/health-systems/Obesity-Update-2014.pdf. (Accessed June 22, 2014)

5. Thangaratinam S, Rogozińska E, Jolly K, Glinkowski S, Duda W, Borowiack $E$ et al. Interventions to reduce or prevent obesity in pregnant women: a systematic review. Health Technol Assess 2012; 16: 1-191

6. Syed W. Fetal outcome in pregnancies complicated by obesity. J Postgrad Med Inst 2015; 29(2): 109-10

7. Felisbino-Mendes MS, Matozinhos FP, Miranda JJ, Villamor E, Velasquez-Melendez G. Maternal obesity and fetal deaths: results from the Brazilian cross-sectional demographic health survey, 2006. BMC Pregnancy and Childbirth 2014; 14:5

8. 1Lingam KMG, Foroohi NG, greer IA, Sattar N. Changes in booking body mass index over a decade: retrospective analysis from a Glasgow Maternity Hospital. Br J Obstet Gynaecol. 2005;112:1431-3.
9. Jaleel R. Impact of maternal obesity on pregnancy outcome. J Surg Pak. 2009:14:2-6.

10. Obesity is a gateway to complications. Ann Pak Inst Med Sci. 2005;1:230-3

11. Andreasen KR, Anderen ML, Schantz AL. Obesity and pregnancy. Acta Obstet Gynecol Scand. 2004;83: 1022-9.

12. Robinson HE, O'Connell CM, Joseph KS, Meleod NL. Maternal outcome in pregnancies complicated by obesity. Obstet Gynaecol. 2005;106:1357-64.

13. Kristensen J, Vester M, Wisborg KK, Kesmodel V, Secher NJ. Prepregnancy weight and the risk of still birth and neonatal death. BGOJ. 2005;112:403-8.

14. Yetal L. Effects of obesity on women's reproduction and complications during pregnancy. Obesity Rev. 2004;5:137-43.

15. Castro L, Avina R. Maternal obesity and pregnancy outcomes. Curr Opin Obstet Gynecol. 2004;14:601-6.

16. Sheiner E, Levy A, Memes TS, Silverberg D, Katz M, Mazor M. Maternal obesity as an independent risk factor for caesarean delivery. Pediatr Perina Epidemiol. 2004:18:196-201.

17. Chauhan SP, Magann EF, Carroll CS, Barrilleaux PS, Scardo JA Martin Jr JN. Mode of delivery for morbidly obese with prior cesarean delivery: vaginal versus repeat cesarean section. Am J Obstet Gynecol. 2001;185:349-54.

18. Catalano PM, Kirwan JP, Haugel-de Mouzon S, King J. Gestational diabetes and insulin resistance: role in short- and long-term implications for mother and fetus. J Nutr. 2003;133(Suppl 2):16745835.

19. O'Brien TE, Ray JG, Chan WS. Maternal body mass index and the risk of preeclampsia: a systematic overview. Epidemiology. 2003;14:368-74

20. Linne Y. Effects of obesity on women's reproduction and complications during pregnancy. Obes Rev. 2004;5:137-43.

21. Sherrard A, Platt RW, Vallerand D, Usher RH, Zhang X, Kramer MS. Maternal anthropometric risk factors for caesarean delivery before or after onset of labour. BJOG. 2007;114:1088-96.

22. Sebire NJ, Jolly M, Harris JP, Wadsworth J, Joffe M, Beard RW, et al. Maternal obesity and pregnancy outcome: a study of 287,213 pregnancies in London. Int $\mathrm{J}$ Obes Relat Metab Disord. 2001;25:1175-82.

23. Cedergren MI. Maternal morbid obesity and risk of adverse pregnancy outcome. Obstet Gynecol. 2004;103:219-24.

24. Callaway LK, Prins JB, Chang AM, McIntyre HD. The prevalence and impact of overweight and obesity in an Australian obstetric population. Med J Aust. 2006;184:56-9

25. Arendas K, Qin Q, Gruslin A. Obesity in pregnancy: pre-conceptional to postpartum consequences. J Obstet Gyaenecol Can. 2008;30:47788.

26. Galtier F, Raingeard I, Renard E, Boulot P, Bringer J. Optimizing the outcome of pregnancy in obese women: from pregestational to long term management. Diab Metab. 2008;34:19-25.

27. Abenhaim HA, Kinch RA, Morin L, Benjamin A, Usher R. Effect of pre pregnancy body mass index categories on obstetrical and neonatal outcomes. Arch GynecolObstet.2007;275:39-43. 